\title{
Influence of drying conditions on the acacia gum particle growth in fluidized bed agglomeration: in-line monitoring of particle size
}

\author{
Rosa, J. G. ${ }^{\text {a,b*, }}$, Nascimento, R. F. ${ }^{\text {a }}$, Andreola, K. ${ }^{a}$ and Taranto, O. P. ${ }^{a}$ \\ ${ }^{a}$ School of Chemical Engineering, University of Campinas, Campinas, São Paulo, Brazil \\ ${ }^{\mathrm{b}}$ Federal Institute of Espírito Santo, campus Vila Velha, Vila Velha, Espírito Santo, Brazil \\ *E-mail of the corresponding author: jugrosa@gmail.com
}

\begin{abstract}
Acacia gum is an important food emulsifier that presents poor instant properties which can be improved by fluidized bed agglomeration. This study investigated the influence of drying conditions on particle growth kinetics using an in-line particle size monitoring by spatial filter velocimetry. The drying conditions varied according to the binder flow rate and the fluidizing air temperature. The particle growth kinectis showed drying conditions dependence. At mild drying conditions the growth rate and the process yield were higher. The in-line particle size monitoring was useful to observe the influence of the drying conditions on the growth kinetics.
\end{abstract}

Keywords: fluidized bed agglomeration; acacia gum; particle growth kinectis; in-line monitoring. 


\section{Introduction}

Acacia gum is a food additive that has several functions and it is mostly used as an emulsifier, for its effectiveness as a long time stabilizer on oil in water emulsions. ${ }^{[1]}$ This gum can be used as a fiber food enricher and as a sucrose replacer, in food formulations, as it causes equivalent sensation in the mouth. ${ }^{[2,3]}$ In addition, it stands out in the food additives market because it is natural, of vegetable origin and does not undergo chemical modifications. ${ }^{[4]}$ The powdered acacia gum is a powder with fine particles, which is difficult to handle, and shows poor dispersion properties. However, the agglomeration process can improve its quality. ${ }^{[5]}$

The particles agglomeration process is used at the pharmaceutical and food industry to improve the characteristics of its powdered products and is often performed in fluidized beds since this equipment provides high rates of heat transfer ${ }^{[6]}$ Fluidized bed agglomeration process involves the particles fluidization by hot air flow and liquid binder atomization onto these particles. The hot air flow is also responsible for the binder evaporation, causing the particles drying and granules to consolidate. The fluidized bed agglomeration is a complex process, that can be influenced by several process parameters like the binder kind and flow, the fluidizing air temperature, and the binder atomization pressure. ${ }^{[7,8]}$

The agglomeration kinetics knowledge is important since the particle size growth is the goal of agglomeration processes. The spatial filter velocimetry (SFV) is an in-line particle size monitoring that provides the granule growth and breakage as a function of granulation time by the measurement of the particle chord lengths. This technique is a new method and has been used successfully in recent studies. ${ }^{[9,10,11]}$ The SFV particle size monitoring can improve the knowledge about what favors particle size increase or its breakage providing important information to the granulation kinetics study.

There are not many experimental studies about food agglomeration kinetics. This work presents a study about powdered acacia gum agglomeration kinetics. The particle growth rate was monitored by in-line particle size monitoring using a spatial filter velocimetry probe for differents drying conditions.

\section{Materials and Methods}

\subsection{Materials}

Spray dried acacia gum (Spraygum BB - Nexira Brasil Comercial) was used as raw material for the agglomeration experiments. The acacia gum wet basis moisture content $\left(X_{w . b .}\right)$ is less than $10.0 \%$. The binder solution was distilled water at room temperature $\left( \pm 27^{\circ} \mathrm{C}\right)$.

\subsection{Characterization of raw and agglomerated acacia gum}

Characterization of raw and agglomerated acacia gum were done based on the median particle size (D50), powder flow characteristics, wetting time $\left(t_{w}\right)$ and $X_{w . b}$. The raw material 
particle size was measured by $S F V$ probe as described above and also by laser diffraction (Mastersizer 3000, MAZ3000 Malvern Instruments, Malvern, UK). Powder flow characteristics were determined by the Carr index (ICarr) values, as described by Turchiuli et al. ${ }^{[12]}$ The $t w$, was the time required for the complete wetting and immersion of $3.0 \mathrm{~g}$ of the sample in $70 \mathrm{ml}$ of water at room temperature. ${ }^{[13]} X_{\text {w.b. }}$ was measured for the raw material, at the end of the bind atomization and at the end of the drying using a halogen moisture analyzer (HR83, Mettler Toledo).

\subsection{Equipment and agglomeration process}

The agglomeration experiments were run in a lab-scale fluidized bed. The fluidized bed chamber had a conical base constructed from transparent acrylic Plexiglas ${ }^{\circledR}$. The bed pressure drop, the air temperature, and the air relative humidity were monitored and recorded by a data acquisition system and processed in the LabVIEW 8.6TM software. Details of the equipment and the data acquisition system are described by Andreola et al. ${ }^{[14]}$ However, in this study, the equipment was operated without air pulsation.

Three different agglomeration conditions were performed, in triplicate, to evaluate the influence of drying conditions on growth kinetics and particle growth rate of powered acacia gum. The process parameters that varied were the binder flow rate $(Q)$ and fluidizing air temperature $\left(T_{\text {air }}\right)$ in the following way: condition $1(\mathrm{E} 1), 1.5 \mathrm{~mL} / \mathrm{min}$ and $85{ }^{\circ} \mathrm{C}$; condition 2 (E2), $2.3 \mathrm{~mL} / \mathrm{min}$ and $75^{\circ} \mathrm{C}$ and condition 3 (E3), 3.0 and $65^{\circ} \mathrm{C}$. The sample mass, initial fluidizing air velocity, the volume of binder, atomization air pressure and atomization nozzle height were kept constant at $0.4 \mathrm{~kg}, 0.28 \mathrm{~m} / \mathrm{s}, 80 \mathrm{~mL}, 6.7 \mathrm{psi}$ and $0.35 \mathrm{~m}$, respectively. The increase in fluidizing air velocity was necessary to maintain a stable fluidization, it was increased (step $0.03 \mathrm{~m} / \mathrm{s}$ ) every $5 \mathrm{~min}$ until $0.43 \mathrm{~m} / \mathrm{s}$.

The process time was different once the binder volume was fixed and the process was carried out until the agglomerated moisture content reached a lower or equal value than that one of the raw material. The E1 had not a drying period and E2 and E3 had an 8 minutes drying period time.

\subsection{Process yield}

The process yield (Yld, \%) was determined based on the initial sample mass $\left(\mathrm{m}_{\text {initial }}\right)$ and the final product $\left(\mathrm{m}_{\text {final }}\right)$ by the Eq. 1 . The $\mathrm{m}_{\text {final }}$ was obtained discounting particles larger than $850 \mu \mathrm{m}$, separated by sieving, from the product mass remained at the end of the experiments. The mean process yield, for each experimental condition, was calculated and a statistical analysis was made by Tukey's test, at a confidence level of $90 \%(\mathrm{p}<0.10)$.

$$
Y=\frac{m_{f}}{m_{i}} \cdot 100
$$




\subsection{In-line particle size measurement and granule growth rate}

The in-line particle size was monitored by Parsum IPP70 probe (Chemnitz, Germany) that employes the SFV principle to measure the "chord" (size) of the particles. Details of the equipment, its accessories and methodology were described by Silva and Taranto. ${ }^{[10]}$ For further analysis of the growth rate of the particle time dependence, an appropriate software, Inline Particle Probe 7.14, obtained the particle size data and sent it to LabVIEWTM 8.6 software via OPC server protocol, this procedure was developed by Silva and Taranto. ${ }^{[10]}$ This system record the particle size and size distribution every 5.12 seconds. The ring buffer size used in the Parsum measurements, 5000 particles, was chosen according to preliminary tests performed (not shown). The median particle size in volume (D50v) was evaluated and the last ten measurements for each run were used to calculate the mean $D 50 \mathrm{v}$ of the agglomerated. The agglomerated $D 50 \mathrm{v}$ for the three experimental condition was compared by Tukey's test, at a confidence level of $90 \%(\mathrm{p}<0.10)$.

The granule growth rate $(R)$ was calculated as defined by $(\mathrm{Eq} 2.) \cdot{ }^{[15]}$ Its value was calculated for each period of 1.7 minutes, that means that $d_{i}$ was the D50v at the initial time and $d_{f}$ was the D50v reported approximately 1.7 minutes after the $d_{i}$ report.

$$
R(\%)=\frac{\left(d_{f}-d_{i}\right)}{d_{i}} .100
$$

\section{Results and discussion}

\subsection{Characterization of raw and agglomerated acacia gum}

The laser diffraction measurements for the raw material were $D 10: 21.9 \pm 0.2 \mu \mathrm{m}, D 50: 65.2$ $\pm 1.0 \mu \mathrm{m}$ and $D 90: 143.6 \pm 2.0 \mu \mathrm{m}$. The values of $D 50 \mathrm{v}$ measured by $S F V$ probe before the spray phase (approximately $111.5 \mu \mathrm{m}$ ) were higher than those obtained by laser diffraction, once the median size obtained by laser diffraction is close to the $S F V$ probe measurement limit, i. e., $50 \mu \mathrm{m}$. However, the values of $D 90 \mathrm{v}$ measured by $S F V$ probe (approximately $154.0 \mu \mathrm{m})$ were close to the off-line measurement, indicating that the probe measurements are reliable.

The final acacia gum powder D50v increased for all experimental conditions (Table 1). The largest increase in particle size occurred at mild drying conditions (E3). At more intense drying conditions the final particle size was smaller and the $D 50 \mathrm{v}$ was statistically equal for the conditions E1 and E2. Similar result was observed by Hirata et al. ${ }^{[16]}$ for agglomeration of similar material using water as a binder. At mild drying conditions, the adhesion among particles is favored by the more wet and sticky surface. Milder conditions also favored higher process yield (Table 1). Under drier conditions (E1) the particle size was smaller and the process time is longer which resulted in larger material elutriation. This was also observed 
during fluid bed agglomeration of rice protein concentrate, very fine particles, by Andreola et al. ${ }^{[14]}$

Table 1: Experimental conditions and their results.

\begin{tabular}{rrrllll}
\hline Conditions & $\mathbf{Q}^{\mathbf{1}}$ & Tair $^{\mathbf{2}}$ & \multicolumn{1}{c}{$\mathbf{D 5 0 v}^{\mathbf{3}}$} & \multicolumn{1}{c}{$\mathbf{Y}^{\mathbf{4}}$} & hout $^{\mathbf{5}}$ & Flowability \\
\hline Raw material & - & - & $65.18 \pm 1.0$ & & & moderate \\
E1 & 1,5 & 85 & $270.7 \pm 19.6^{\mathrm{a}}$ & $50.4 \pm 6.0^{\mathrm{a}}$ & $34.9 \pm 2.7$ & moderate \\
E2 & 2,3 & 75 & $275.3 \pm 8.2^{\mathrm{a}}$ & $61.4 \pm 6.0^{\mathrm{a}, \mathrm{b}}$ & $47.0 \pm 6.4$ & moderate \\
E3 & 3,0 & 65 & $285.7 \pm 13.7^{\mathrm{b}}$ & $64.3 \pm 6.0^{\mathrm{b}}$ & $53.4 \pm 8.2$ & moderate \\
\hline
\end{tabular}

$\overline{{ }^{1} \text { Binder flow rate }(\mathrm{mL} / \mathrm{min}) ;{ }^{2} \text { Fluidizing air temperature }\left({ }^{\circ} \mathrm{C}\right) ;{ }^{3} \text { Median particle size in volume }(\mu \mathrm{m})}$; ${ }^{4}$ Process yield (\%) and ${ }^{5}$ Mean relative humidity of the warm-moist air flowing out of the bed (\%).

The agglomeration process presented different results concerning the handling properties, wetting time and flowability. All agglomeration conditions improved the acacia gum instant properties. The raw material did not get completely wetted even after $600 \mathrm{~s}$, on the other hand the agglomerated were completely wetted in less than $5 \mathrm{~s}$. Regarding to the flowability, agglomerated acacia gum was similar to the raw material (Table1).

\subsection{Particle growth rate}

The triplicate of the granule growth kinetics for the different experimental conditions is presented in Fig. 1, it shows that there was reproducibility of the particle growth behavior for the process. Although the final particle size was similar for the three experimental condition, the particle growth behavior was different.

At condition E1, with more intense drying condition, the particle growth was almost continuous (Fig. 1(a)). However, the particle size enlargement was slower compared to the other two conditions (Fig. 1 (d)). At that condition, binder availability is smaller and consequently less liquid bridges were formed between the particles.

The particle growth rate $(R)$ for the three experimental is presented in Fig. 2. The particle growth rate oscillated during the process showing that the particle size growth results from positive a balance from agglomeration and break.

The $\mathrm{R}$ for the $\mathrm{E} 1$ condition confirms a slower size enlargement presented since it presents the lowest mean value (Fig. 2). It oscillated around 2\% during the process and presented few negative values that indicates an absence of particle breaking by attrition and collision. This is observed because in that condition a constant wetting occurred causing a continuous increasing of the particle size. In that condition, the fluidization was more vigorous which associated with the highest temperature and time of process could have contributed to form stronger and larger granules as observed by Andreola et al. ${ }^{[14]}$ 

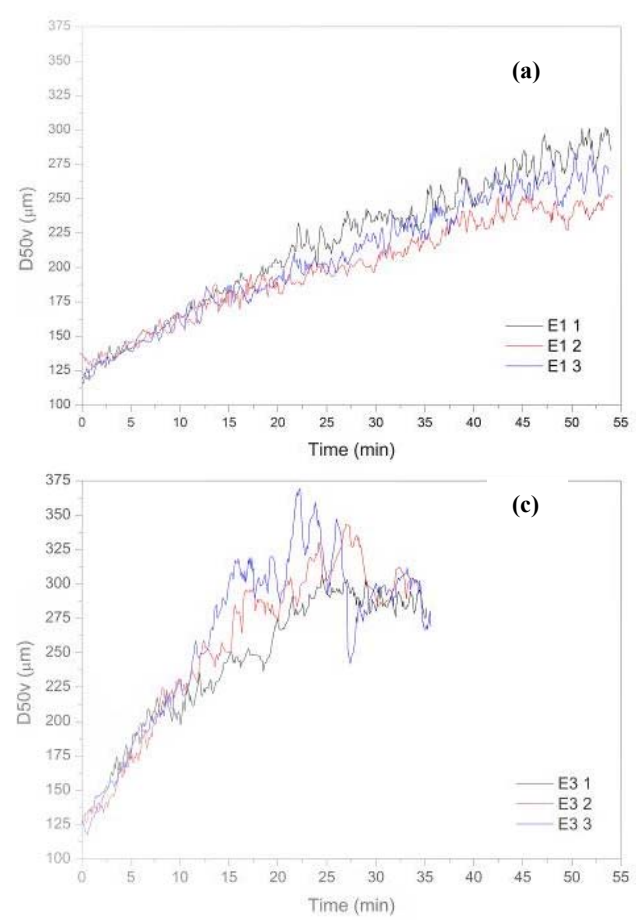
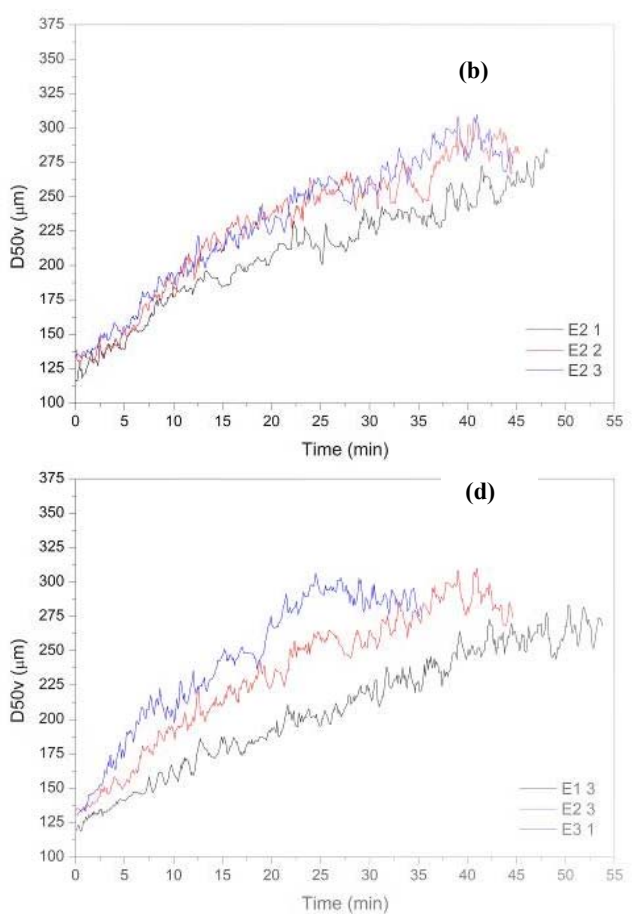

Figure 1: In-line D50v triplicate data for (a) E1, (b) E2, (c) E3. Comparative in-line D50v data for $E 1, E 2$ and $E 3(d)$.

The experimental condition E2 presented a larger particle growth at the beginning of the process that decreased with the binder spraying time (Fig. 1(b)). In that condition, the particle growth rate (Fig. 2) presented a smaller oscillation, compared to the other conditions, and a downward trajectory with the progress of the process. The particle growth rate presents some negative values, especially in the drying period, indicating that there were some breaking of particles by attrition and collision.

The milder drying condition E3 presented the higher particle growth at the beginning $(\mathrm{R}>$ $10 \%$, Fig. 2) that results in the largest particle size recorded (D50v $>350 \mu \mathrm{m}$ ). However a decreasing at the D50v during the drying period was observed (Fig. 1(c)). The R for condition E3 had a higher oscillation and more expressive negative value in comparison to the condition E2. It is related to the fact that the wetter and larger granules are more susceptible to the broken down by attrition. ${ }^{[17]}$ Under these conditions, the worst fluidization regime was observed due to the formation of large agglomerates, which may also have impaired the consolidation of the granules. In spite of the breaks, the final particle size was the largest of the three conditions. 


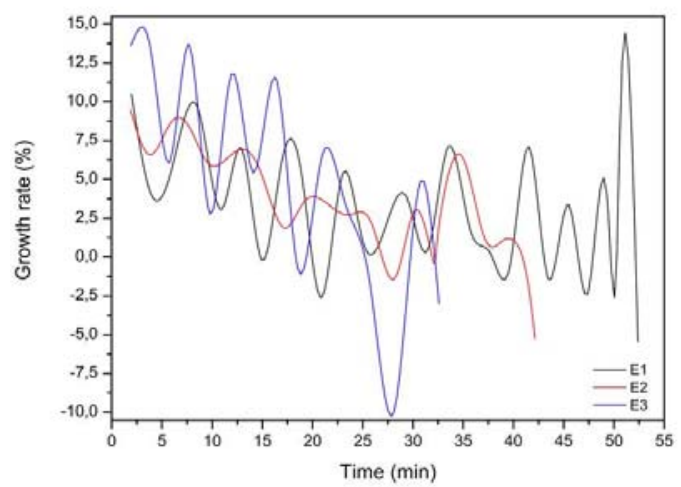

Figure 2: Particle growth rate for the different experimental conditions.

\section{Conclusion}

The fluidized bed agglomeration process improved the acacia gum powder instant properties. The in-line SFV particle size measurement made it possible to observe the growth rate of the particle. The operating conditions influenced both the particle final D50v and the behavior of the granule growth kinetics. The milder drying condition provided larger granules and higher yield in the process. However, it is interesting to analyze an intermediate condition between E2 and E3 for the production of larger and more stable granules.

\section{References}

[1] Dror, Y; Cohen, Y; Yerushalmi-Rozen R. Structure of Gum Arabic in Aqueous Solution. Journal of Polymer Science: Part B: Polymer Physics 2006, 44, 3265-3271.

[2] Phillips, G.O.; Ogasawara, T.; Ushida, K. The regulatory and scientific approach to defining gum arabic (Acacia senegal and Acacia seyal) as a dietary fibre. Food Hydrocolloids 2008, 22, 24-35.

[3] Baray, S. Acacia Gum. In: Cho, S. S.; Samuel, P. Fiber Ingredients - Food Applications and Health Benefits. [S.1.]: CRC Press, 2009, 121-134.

[4] Islam, A.M.; Phillips, G.O.; Sljivo, A.; Snowden, M. J.; Williams, M. A. A review of recent developments on the regulatory, structural and functional aspects of gum arabic. Food Hydrocolloids 1997, 11 (4), 493-505.

[5] Fuchs, M.; Turchiuli, C.; Bohin, M.; Cuvelier, M.E.; Ordonnaud, C.; Peyrat-Maillar, M.N.; Dumoulin, E. Encapsulation of oil in powder using spray drying and fluidised bed agglomeration. Journal of Food Engineering 2006, 75, 27-35.

[6] Kunii, D.; Levenspiel, O. Fluidization Engineering. 2.ed. New York: John Wiley, 1991, 489 p. 
[7] Hemati, H., Cherif, R., Saleh, K., Pont, V. Fluidized bed coating and granulation: influence of process-related variables and physicochemical properties on the growth kinetics. Powder Technology 2003, 130, 18-34.

[8] Tan, H.S.; Salman, A.D.; Hounslow, M.J. Kinetics of fluidised bed melt granulation I: the effect of process variables. Chemical Engineering Science 2006, 61, 1585-1601.

[9] Wiegel, D.; Eckardt, G.; Priese, F.; Wolf, B. In-line particle size measurement and agglomeration detection of pellet fluidized bed coating by Spatial Filter Velocimetry. Powder Technology 2016, 301, 261-267.

[10] Silva, C.A.M; Taranto, O.P. Real-time monitoring of gas-solid fluidized-bed granulation and coating process: evolution of particle size, fluidization regime transitions, and psychometric parameters, Drying Technology 2015, 33, 1929-1948.

[11] Burggraeve, A.; Kerkhof, V.D.; Hellings, M.; Remon J.P., Vervaet; De Beer, T. Evaluation of in-line spatial filter velocimetry as PAT monitoring tool for particle growth during fluid bed granulation. European Journal of Pharmaceutics and Biopharmaceutics 2010, 76, 138-146.

[12] Turchiuli, C.; Eloualia, Z.; Mansouri, N.; Dumoulin, E. Fluidised bed agglomeration: agglomerates shape and end-use properties. Powder Technology 2005, 157, 168-175.

[13] Hogekamp, S.; Schubert, H. Rehydration of food powders. Food Science and Technology International 2003, 9, 223-235.

[14] Andreola, K.; Silva, C.A.M.; Taranto, O.P. Production of Instant Rice Protein Concentrate by Rotating Pulsed Fluidized Bed Agglomeration using Hydrolyzed Collagen Solution as Binder. Chemival Engineering Transactions 2016, 49, 115-120.

[15] Hu, X.; Cunningham, J.C.; Winstead, D. Study growth kinetics in fluidized bed granulation with at-line FBRM. International Journal of Pharmaceutics 2008, 347, 54 61.

[16] Hirata, T.A.M; Dacanal, G.C.; Menegalli, F.C. Effect of operational conditions on the properties of pectin powder agglomerated in pulsed fluid bed. Powder technology 2013, $245,174-181$.

[17] Reynolds, G.K., Fu, J.S., Cheong, Y.S., Hounslow, M.J., Salman, A.D. Breakage in granulation: a review. Int. J. Pharm. 200, 60, 3969-3992. 